\title{
MOBILIZATION OF CARDIOVASCULAR FUNCTION AT ONSET OF DOSED AEROBIC AND ALL-OUT ANAEROBIC WORKOUTS
}

\author{
Jonas Poderys, Arūnas Emeljanovas \\ Lithuanian Academy of Physical Education, Kaunas, Lithuania
}

\begin{abstract}
Jonas Poderys. Professor, Habilitated Doctor of Biomedical Sciences; Science executive in the Laboratory of Kinesiology. The field of scientific research — improvement of human health and physical working capacity.
\end{abstract}

\begin{abstract}
The objective of this study was to compare the peculiarities in the mobilization of cardiovascular function at the onset of an exercise test in dependence on age and the type of adaptation to physical loads. The study's participants were boys of $11,12,13$ and 14 years old and adults, i. e. 17 voluntary students who were not engaged in sports training and welltrained athletes (all participants were members of various national teams), i. e. 23 athletes in the endurance group, 19 in the sprint group and 21 - in the combative sports group (box, judo and wrestling). The subjects underwent: 1) Roufier's test (30 squats per 45 seconds); 2) a 30-second duration maximal vertical jump test. A computerized electrocardiogram (ECG) system "Kaunas-Load" was employed for the 12-lead ECG recording and analysis during the performance of workloads. A computerized program allowed to measure the ratio of JT and RR intervals (JT / RR) and the velocity of adaptation of cardiovascular system to exercise, i.e. the index of velocity of adaptation $(V$, $)$, by calculation the difference between the relative changes of $J T$ and RR intervals as a difference: $V_{A d{ }^{\prime}}=\left(J t_{i} / J T_{0}\right) 100 \%-\left(R r_{i} /\right.$ $R R$ ) $100 \%$. The results obtained during the study allowed to conclude that faster adaptation at the onset of the exercise is rather characteristic for younger persons but the type of the exercise performed during the long term training process plays a significant role in the developing and improving the velocity of adaptation of cardiovascular system. A faster adaptation at the onset of the exercise is a more characteristic feature for the trained athletes in sprint events and combative sports than the representatives of the endurance group or non-athletes. One of the effects of long term adaptation to exercise is a smaller mobilization of cardiovascular system at the onset of the dosed aerobic and all-out anaerobic exercise and the endurance exercise has the most influence on it.
\end{abstract}

Keywords: cardiovascular system, adaptation, exercise test.

\section{INTRODUCTION}

$\mathrm{A}$ $t$ the onset of an exercise a lot of body systems adapt to the variations of load. Consequently, a number of indices exist for the measurement of response of body functions to workload. In practice, the response to exercise can be evaluated by measuring the changes in the performance of one or another system (Hughson, Tschakovsky, 1999; Hedelin et al., 2000; Porter et al., 2001; Rothe, Gersting, 2002). Recently, more frequent research has been carried out to examine the response of body to exercise as an integral impact on the body (Ahlborg et al., 1996; Ursino, 1998; Biggiero, 2001). The cardiovascular system is one of the holistic systems of the human body why the reactions of cardiovascular system to the constantload test or all-out test allow us to assess the functional peculiarities of the body (Vainoras, 2002).

The fast mobilization of body functions at the onset of an exercise is very important in many kinds of sport and there are a lot of situations in competitive sports when this ability is the determinant factor or important element of functional and performance capabilities (Платонов, 2004). On the other hand the effects of an exercise to growing and developing of movement abilities are dependent on the intensity 


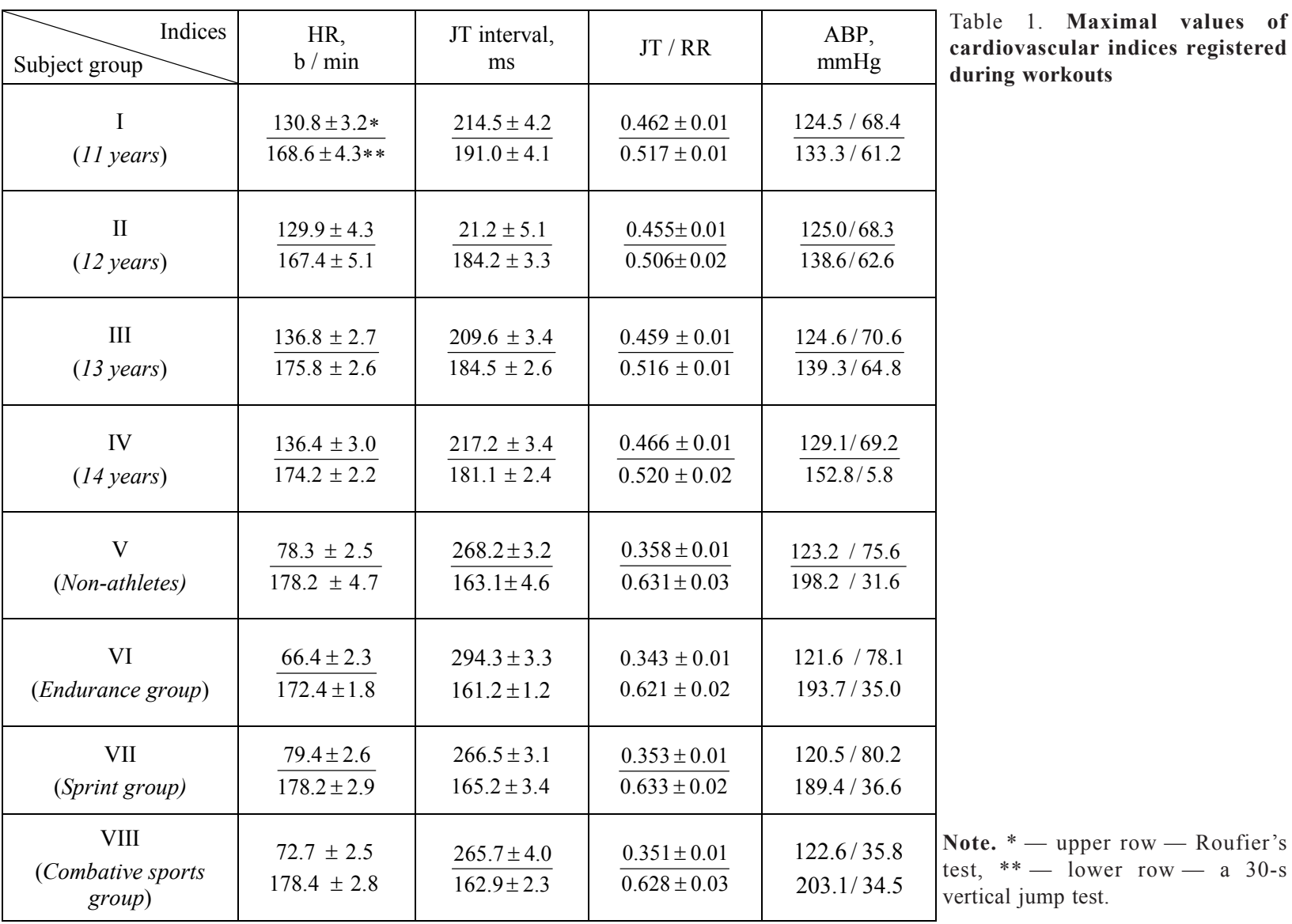

of an exercise, which from the physiological point of view is a level of mobilization of body functions during exercising. The objective of this study was to find out the peculiarities in the mobilization of cardiovascular function at the onset of an exercise test in dependence on age and the type of adaptation to physical loads.

\section{MATERIAL AND METHODS}

The study participants were four groups of boys: 11 years old $(n=22), 12$ years old $(n=18)$, 13 years old $(n=25)$ and 14 years old $(n=20)$ and four adult groups (non-athletes, sprint, endurance and combative sports) The nonsportsman group contained 17 voluntary students who were not engaged in sports training (aged $20.9 \pm 1.21$, body mass index $-22.3 \pm 0.38$ ) Well-trained athletes fell into three groups (all participants were members of various national teams), i. e. 23 athletes were in the endurance group; 19 - in the sprint group and $21-$ in the combative sports group (box, judo and wrestling).

The local ethical committee has approved this study protocol. The subjects underwent: 1) Roufier's test (30 squats per 45 seconds); 2) a 30-second duration maximal vertical jump test.

Arterial blood pressure (ABP) was measured by using Korotkoff's method and a computerized electrocardiogram (ECG) analysis system "KaunasLoad", developed at the Kaunas Medical University Institute of Cardiology, was employed for the 12-lead ECG recording and analysis. The changes in RR interval or heart rate (HR), JT interval, and in the ratio of intervals JT / RR were analysed. The computerized program allowed us to evaluate the velocity of adaptation of cardiovascular system to exercise, i. e. the index of velocity of adaptation $\left(\mathrm{V}_{\mathrm{Ad}}\right)$, by calculation the difference between the relative changes of JT interval and RR interval as a difference: $\mathrm{V}_{\mathrm{Ad}}=(\mathrm{Jti} /$ JT0) $100 \%$ - (Rri / RR0) 100\%. The significance of the difference between parametric and nonparametric values was evaluated by computing criterion $t$. The difference has been considered statistically reliable, when $\mathrm{p}<0.05$ (95 CI).

\section{RESULTS}

Table 1 presents the maximal values of cardiovascular indices registered during the performance of exercise tasks. All values of heart 


\begin{tabular}{|c|c|c|c|}
\hline \multirow{10}{*}{$\begin{array}{l}\text { Table } 2 \text {. The values in velocity of } \\
\text { adaptation }\left(\mathrm{V}_{\mathrm{Ad}}\right) \text { of cardiovascular } \\
\text { system at onset of Roufier's test } \\
\text { (aerobic workout), } 30 \text { second all-out } \\
\text { test in jumping (anaerobic workout) }\end{array}$} & \multirow{2}{*}{${ }_{\text {Subject group }}$ Exercise test } & \multicolumn{2}{|c|}{ Exercise test } \\
\hline & & Roufier test & a 30 -s vertical jump test \\
\hline & $\begin{array}{c}\mathrm{I} \\
(11 \text { years })\end{array}$ & $13.4 \pm 1.55$ & $11.9 \pm 0.93$ \\
\hline & $\begin{array}{c}\mathrm{II} \\
(12 \text { years })\end{array}$ & $13 \pm 1.58$ & $12.7 \pm 1.35$ \\
\hline & $\begin{array}{c}\text { III } \\
(13 \text { years })\end{array}$ & $9.3 \pm 1.16$ & $10.4 \pm 1.1$ \\
\hline & $\begin{array}{c}\mathrm{IV} \\
(14 \text { years })\end{array}$ & $13 \pm 0.96$ & $12.7 \pm 1.14$ \\
\hline & $\begin{array}{c}\mathrm{V} \\
\text { (Non-sportsmen) } \\
\end{array}$ & $21.4 \pm 1.33$ & $22.1 \pm 1.33$ \\
\hline & $\begin{array}{c}\text { VI } \\
\text { (Endurance group) }\end{array}$ & $19.8 \pm 1.34$ & $20.6 \pm 1.31$ \\
\hline & $\begin{array}{c}\text { VII } \\
\text { (Sprint group) }\end{array}$ & $16.3 \pm 1.33$ & $16.9 \pm 1.32$ \\
\hline & $\begin{array}{c}\text { VIII } \\
\text { (Combative sports group) }\end{array}$ & $17.2 \pm 1.29$ & $17.8 \pm 1.30$ \\
\hline
\end{tabular}

rate, JT interval and arterial blood pressure correspond with the data presented in publications of other scientists. As an example, the differences in the reactions of arterial blood pressure between adolescents and adults can be explained by the great elasticity of blood vessels in young age (Shephard, 2001).

The results obtained during the study showed that the velocity of adaptation at the onset of the dosed aerobic and all-out anaerobic exercise depends on age. All groups of the boys have a significantly $(p<0.05)$ faster adaptation than adult groups. The slowest velocity of adaptation has been showed by the adult non-athletes $(21.4 \pm 1.33 \%$ - when performing Roufier's test and $22.1 \pm 1.33 \%$ - when performing the jumping task. The results presented in Table 1 demonstrate that the velocity of adaptation at the onset of the exercise depends on the residual effects of training but not on the type of exercisetest. The significant differences between values in the velocity of adaptation in response to exercising were not found when three various test protocols were used (Roufier's test, a 30-second duration maximal vertical jump test). The fastest adaptation at the onset of the exercise was in the sprint group $(16.3 \pm 1.33 \%)$. The values of velocity of adaptation in the endurance group were $19.8 \pm 1.34 \%$. The difference between the sprint and endurance groupings was statistically significant $(p<0.05)$. The velocity of adaptation in the group of non-athletes was the slowest $21.4 \pm 1.33 \%$. Summarizing, the faster adaptation at the onset of the exercise is quite in character for the sprint and combative sports than the endurance or non-athlete contingents.

Figure presents the comparison of the mobilization of cardiovascular function during various exercise tests. The greatest difference among the groups was revealed by a 30 -second duration all-out maximal vertical jump test. The greatest values were in the group of non-athletes and the least - in the endurance group. The difference between these contingents was statistically significant $(p<0.05)$. The Roufier's test also revealed the differences between the groups.

\section{DISCUSSION}

The fast mobilization of body functions at the onset of an exercise is very important in many kinds of sport and there are a lot of situations in competitive sport when this ability is a decisive factor or important element of functional capability. There are not so many integral methods designed for the assessment of individual peculiarities of mobilization of body functions during exercising. The energy system's approach is fit enough for explanation of matters but it is 


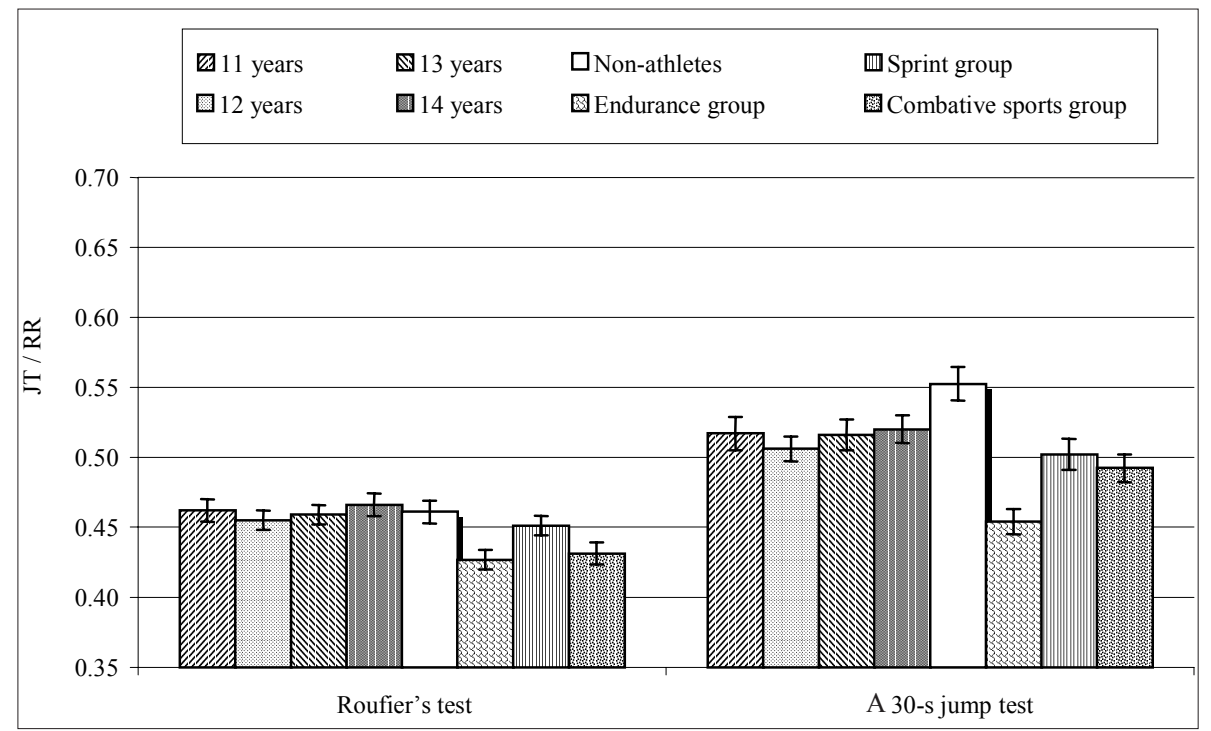

Fig. Mobilization of cardiovascular function during the exercise tests (maximal values in changes of the ratio of $J T$ interval and $R R$ interval (JT / RR))

difficult to use it in practice. On the other hand, given repeated reproduction over the years, these early attempts have led to two common misconceptions in the exercise science and coaching professions (Green, 1995). First, that the energy systems respond to the demands of intense exercise in an almost sequential manner, and secondly, that the aerobic system responds slowly to these energy demands, thereby playing little role in determining performance over short durations. More recent research suggests that energy is derived from each of the energyproducing pathways during almost all exercise activities. The duration of all-out exercise at which equal contributions are derived from the anaerobic and aerobic energy systems occurs is considerably earlier than has traditionally been suggested (Spencer et al., 1996; Gastin, 2001; Green, 1995). We must point out that the last year studies have shown a great importance of complexity in body functioning (Tulpo et al., 2002; Vainoras, 2002). Since the cardiovascular system is one of the constituent parts and a holistic system of the body, therefore, the reactions of cardiovascular system to constantload tests or all-out tests allows one to assess the functional capabilities and functional peculiarities of the body (Vainoras, 2002).

Concerning the problem of evaluation of the peculiarities in the mobilization of the body functioning during exercising the two factors are important: first, the velocity of adaptation at the onset of an exercise, and second, to what extent the body function was mobilized. The results obtained in this study have shown what a significant role in developing and improving the velocity of adaptation of cardiovascular system at the onset of the exercise is played by the exercise type or the type of adaptation. The main differences in the content of training between the sprint and endurance groups consist in prevailing the interval methods of training in the sprint group and sustained exercise in endurance events (Платонов, 2004). Sudden changes in intensity in workloads during the fight are the typical characteristics of combative events. Thus, these changes could be a possible explanation of differences in the values of the velocity of adaptation among the endurance and sprint or combative contingents found out during this study.

Individual peculiarities and differences between various groups can be assessed making use of the index of velocity of adaptation $\left(\mathrm{V}_{\mathrm{Ad}}\right)$, which represents the difference between the relative changes of RR and JT intervals of ECG. Our previous studies (Poderys, 2000; Poderys, 2002) have shown that the velocity of adaptation at the onset of the exercise depends rather on the functional state or residual effects of training than on the type of exercise-test. During the study designed to evaluate the changes in the velocity of adaptation in the sprint group significant changes under the influence of concentrated heavy training loads have been found, i. e. $16.3 \pm 1.33 \%-$ before the training, $26.2 \pm 1.42 \%$ - after two weeks of heavy training, and $20.1 \pm 1.35 \%-$ after one week of recovery accordingly (Poderys, 2002). All this allows us to conclude that individual peculiarities and differences between contingents in the velocity of adaptation of cardiovascular system at the onset of the exercise can be evaluated making use of the difference 
between the relative changes of RR and JT intervals of ECG. The results obtained during this study showed that faster adaptation at the onset of the exercise is rather characteristic for younger persons but the type of exercise performed during the training process plays a significant role in the developing and improving the velocity of adaptation of cardiovascular system. A faster adaptation at the onset of the exercise is rather characteristic for the sportsmen trained in sprint events and combative sports than the representatives of the endurance group or nonathletes.

The studies designed to assess the individual peculiarities of body functioning during the workloads usually have a task to evaluate to what extent the body function was mobilized during the performance of the task. Absolute values of heart rate during exercising can be used for these purposes. Such methods are practical but not precise for outlining to what extent the mobilization of cardiovascular system occurred (Vainoras, 1996, 2002; Poderys, 2000). A special study performed by V. G. Bochkov in 1986, has shown that the activation of physiological systems could be expressed by normalized values in the ratio of underlying indices of the physiological system. These underlying indices of cardiac function can be the ratio of JT and RR intervals (Vainoras, 1996). The JT interval is not independent of the ventricular depolarisation pattern and can be used as an accurate means of following the duration of ventricular depolarisation (Banker et al., 1997) and its changes interrelate with the changes in the intensity of metabolism (Vainoras, 1996). The results obtained during this study have shown that the ratio JT / RR can be useful for outlining to what extent a cardiovascular function was mobilized. As it was found during the incremental increase in workload (till the inability to continue the task) the ratio in JT / RR has varied very closely or even coincided as V. G. Bochkov established it in 1986. Accordingly to V. G. Bochkov these biological constants can be expressed mathematically $(1 / \mathrm{e}=0.368$ and $1-$ $1 / \mathrm{e}=0.632)$. Our previous studies showed that the ratio of JT and RR intervals (JT / RR) of ECG provides the information concerning the dynamics of mobilization of cardiovascular system during the workouts. When performing dosed workloads (Roufier's test - aerobic workout) and during a 30 second all-out test in jumping (anaerobic workout) the changes in the ratio of JT / RR were in dependence on age and on performance abilities (training experience) and functional state. One of the effects of long term adaptation to exercise is a smaller mobilization of cardiovascular system at the onset of the dosed aerobic and all-out anaerobic exercise. The endurance-trained athletes have performed both exercise tasks with smaller changes in the ratio of JT / RR, i. e. with the smallest mobilization of cardiovascular system at the onset of the exercise.

\section{CONCLUSIONS}

1. Faster adaptation at the onset of an exercise is a characteristic feature for younger persons but the type of exercise performed during the longterm training process plays a significant role in the developing and improving the velocity of adaptation of cardiovascular system. A faster adaptation at the onset of an exercise is rather characteristic for the trained athletes in sprint events and combative sports than the representatives of endurance group or nonathletes.

2. One of the effects of long term adaptation to exercise is a smaller mobilization of cardiovascular system at the onset of the dosed aerobic and all-out anaerobic exercise and the endurance exercise has the most influence on it. 


\section{REFERENCES}

Ahlborg, G., Ottoson Seeberger, A., Lundberg, J. M. (1996). Central and regional hemodynamic effects during infusion of big endothelin - in healthy humans. Journal of Applied Physiology, 80, 1921-1927.

Banker, J., Dizon, J., Reiffel, J. (1997). Effects of the ventricular activation sequence on the JT interval. American Journal of Cardiology, 79 (6), 816-819.

Biggiero, L. (2001). Sours of complexity in human systems. Journal of Non-Linear Dynamics. Psychology and Life Sciences, 5 (1), 379.

Gastin, P. B. (2001). Energy system interaction and relative contribution during maximal exercise. Sports Medicine, 31 (10), 725-741.

Green, S. (1995). Measurement of anaerobic work capacities in humans. Sports Medicine, 19 (1), 32-42.

Hedelin, R., Kentta, G., Wiklund, U., Gjierle, P., Herikson-Larsen, K. (2000). Short-term over training: Effect of performance, circulatory responses, and heart rate variability. Medicine \& Science in Sports \& Exercise, $32,1480-1484$.

Hughson, R. L., Tschakovsky, M. E. (1999). Cardiovascular dynamics at the onset of exercise. Medicine \& Science in Sports \& Exercise, 31 (7), 10051010.

Poderys, J. (2002). Acute and chronic adaptation of cardiovascular function to sprint or endurance training. Ugdymas. Küno kultūra. Sportas (Education. Physical Training. Sport), 3, 44-48.

Poderys, J. (2000). Acute and Chronic Adaptation of Cardiovascular System to Exercise (Summary of Research Report Presented for Habitation). Kaunas University of Medicine.

Porter, H., Louisy, F., Laude, D., Berthelot, M., Guezennec, C. Y. (2001). Intense endurance training on heart rate and blood pressure in runners. Medicine \& Science in Sports \& Exercise, 33, 1120-1125.
Rothe, C. F., Gersting, J. H. (2002). Cardiovascular interaction; an interactive tutorial and mathematical model. Journal of Advances in Physiology Education, 26 (2), 98-109.

Shephard, R. J. (2001). Absolute versus relative intensity of physical activity in a dose-response context. Medicine \& Science in Sports \& Exercise, 33 (6 Suppl), 400-418; $419-420$.

Spencer, M. R., Gastin, P. B., Payne, W. R. (1996). Energy system contribution during 400 to 1500 metres running. IAAF quarterly. New Studies in Athletics, 17 (4), 59-65. Tulpo, M. P., Hughson, R. L., Miakikalio, T. H. (2002). Effects of exercise and passive head - up tilt on fractal and complexity properties of heart rate dynamics. AJP Heart and Circulatory Physiology, 280, 3, H $18081-$ 1087.

Ursino, M. (1998). Interaction between carotid baroregulation and the pulsating heart: A mathematical model. American Journal of Physiology, 44, 1733-1747.

Vainoras, A. (2002). Functional model of human organism reaction to load evaluation of sportsmen training effect. Ugdymas. Kūno kultūra. Sportas (Education. Physical Training. Sport), 3 (44), 88-93.

Vainoras, A. (1996). Investigation of the Heart Repolarization Process during Rest and Bicycle Ergometry (100-lead and standard 12-lead ECG data). Synopsis of a Dr. Sc. habil. thesis. Kaunas. P. 64.

Бочков, В. Г. (1986). Многовариантность регулирования в биологических системах и новые физиологическые константы: автореф. дисс. на соиск. учён. степ. канд. ьиологических наук. Киев.

Платонов, В. Н. (2004). Соревновательная деятельность в спорте. В кн.: Система подготовки спортсменов в олимпийском спорте. Киев. С. 109132 .
Received on May 18, 2005 Accepted on June 30, 2005
Jonas Poderys

Lithuanian Academy of Physical Education Sporto str. 6, LT-44221 Kaunas

Lithuania

Tel +37037302650

E-mail L.Poderys@1kka.1t 